Buchanan, W. W., et al. (1.966). Gut, 7, 351

Chisholm, D. M., and Mason, D. K. (1968). Fournal of Clinical Pathology, 21,656 .

Copeman, W. S. C. (1963). British Medical fournal, 2, 1526.

Ellman, P., Weber, F. P., and Goodier, T. E. W. (1951). Quarterly fournal of Medicine, 20, 33.

Fenster, L. F., Buchanan, W. W., Laster, L., and Bunim, J. J. (1964). Annals of Internal Medicine, 6i, 498.

Godtfredsen, E. (1947). Transactions of the Ophthalmological Society of the United Kingdom, 47, 175.

Hinchcliffe, R. (1959a). Acustica, 9, 303.

Hinchcliffe, R. (1959b). Fournal of Laryngology and Otology, 73, 830.

Hradský, M., Bartoš, V., and Keller, D. (1967). Gastroenterologica, 108, 252

Jebavỹ, V. Z., Hradskȳ, M., and Herout, V. (1961). Zeitschrift für die gesamte innere Medizin und ihre Grenzgebiete, 16, 930.
Park, W. M., and Mason, D. K. (1966). Radiology, 86, 116.

Ropes, W. M., Bennett, G. A., Cobb, S., Jacox, R., and Jessar, R. A. (1958). Bulletin on Rheumatic Diseases, 9, 175

Sjögren, H. (1943). A New Conception of Keratoconjunctivitis Sicca (Keratitis Filiformis in Hypofunction of the Lachrymal Glands), translated by J. B. Hamilton. Sydney, Australasian Medical Publishing Company.

Szanto, L., Farkas, K., and Gyulai, E. (1957). Rheumatism, 13, 60 .

Talal, N., and Bunim, J. J. (1964). American fournal of Medicine, 36, 529.

Talal, N., Sokoloff, L., and Barth, W. F. (1967). American fournal of Medicine, 43, 50 .

Whaley, K., Chisholm, D. M., Downie, W. W., Dick, W. C., and Williamson, K., Chisholm, D. M., Downie, W. W., Dick, W. C.,
son). Acta rheumatologica Scandinavica, 14, 298.

Whaley, K., et al. (1969). Clinical and Experimental Immunology, 4, 273.

Williamson, J., Cant, S., Mason, D. K., Greig, W. R., and Boyle, J. A. (1967). British fournal of Ophthalmology, 51, 721.

\title{
Further Experience with Azathioprine in Rheumatoid Arthritis
}

\author{
JACQUELINE HARRIS， J. D. JESSOP， D. MARK CHAPUT DE SAINTONGE
}

British Medical fournal, 1971, 4, 463-464

\section{Summary}

Azathioprine has been shown to reduce the steroid requirements of patients with severe rheumatoid arthritis. Twenty-seven patients treated with azathioprine have now been followed up for 30 months. At the end of this period only 10 were still taking the drug. Maximum steroid reduction occurred within the first 12 months of treatment. Some steroid-sparing effect seemed to persist after the drug was stopped. There was no evidence that azathioprine prevented radiological deterioration. No deaths occurred and toxic effects always reversed on stopping the drug.

\section{Introduction}

Azathioprine has been used in the treatment of rheumatoid arthritis since 1964; the results of this therapy have recently been reviewed in detail by Currey (1971). Though many reports are encouraging it is unfortunate that most studies have been uncontrolled and are therefore difficult to assess. However, a double-blind controlled study of azathioprine against placebo in patients with rheumatoid arthritis carried out at the London Hospital has been reported (Mason et al., 1969). It was found that steroid requirements were significantly reduced in the azathioprine-treated group after 12 months.

When the results of the trial were available it became unethical to withhold azathioprine from those patients in the placebo group who had failed to reduce steroid dosage, and a controlled follow-up was therefore impossible. The azathioprine-treated group has been followed for 30 months after entry to the trial and this report describes their progress.

Department of Rheumatology, The London Hospital, London E1 1BB JACQUELINE HARRIS, M.R.C.P., Senior Registrar

J. D. JESSOP, M.R.C.P., M.R.C.P.I., Senior Registrar (Present position: Consultant Physician, Department of Physical Medicine and Rheumatology, University Hospital of Wales, Cardiff)

London Hospital Medical College, London E1 2 AD

D. MARK CHAPUT DE SAINTONGE, B.SC., M.R.C.P., Lecturer in Clinical Pharmacology

\section{Patients and Methods}

The design of the trial was described in the original report (Mason et al., 1969). Fifty-four patients with severe, seropositive, erosive rheumatoid arthritis entered the trial and 49 received treatment for long enough to be analysed. Most had considerable functional impairment and all had been treated with at least $5 \mathrm{mg}$ of prednisolone daily (range 5-20 mg) for six months. Steroid requirements were always kept at the lowest acceptable level and all patients were maintained on a stable dose for two months before starting the trial tablets.

Twenty-seven patients received azathioprine $2.5 \mathrm{mg} / \mathrm{kg} /$ day in divided doses. When the trial was completed and the nature of the treatment revealed, the clinicians were allowed to decide whether individual patients should continue to take azathioprine or not.

\section{Results}

Only 10 of the 27 azathioprine-treated patients were still taking the drug at 30 months; reasons for discontinuing azathioprine are shown in the Table.



Steroid Requirements. - Reduction in steroid requirement may be best expressed as a fall in the log dose. The effect of this transformation is to give similar weight to falls which are the same proportion of the starting dose, even though their absolute values may be different. The steroid requirements of the patients are shown in the Chart. There was a significant fall during the first 12 months of treatment $(P=0.05, t$ test, 2-tailed). In order to define the period of maximum benefit in those patients who responded to azathioprine, a separate line shows the steroid requirements of the group, omitting eight patients who were withdrawn from treatment because of failure to respond. This shows more clearly that the maximum steroid reduction occurred during the first 12 months and after that 
there was no further significant change. Seven patients who had completed 12 months' treatment with azathioprine were later withdrawn because of toxicity (six) or transfer to another area (one). Eighteen months after stopping azathioprine the patients in this group still needed a significantly lower dose of steroids than they did on entry into the trial $(P=0 \cdot 05$, related $t$ test, 2-tailed). Though the number of patients is small and a control group is not available for comparison, this result suggests that the steroid-sparing action of azathioprine may persist for a considerable period after its withdrawal.

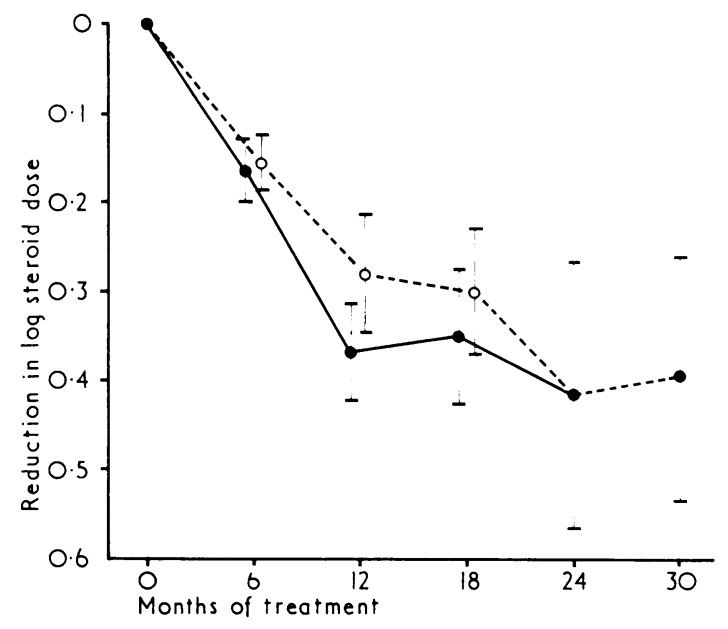

Fall in steroid requirement ( \pm S.E.M.) of all 27 patients started on azathioprine (o - - - - o) compared with the fall in the 19 patients who responded to azathioprine (omitting eight who werc withdrawn from treatment because of failure to respond)

Radiological Changes.-Two observers analysed radiographs of hands and feet without reference to the date of the film. In 12 patients there was definite evidence of progressive erosive change while they were being treated with azathioprine, and in eight this continued to occur after 12 months' treatment. These radiographs, however, showed severe destructive changes before treatment was started, which made measurement of progressive changes difficult.

Toxicity.-Seven patients discontinued azathioprine at some time during the 30 months because of toxicity (see Table). These effects were reversed when the drug was withdrawn. No patient in this group died but one patient from the placebo group who was subsequently treated with azathioprine for 12 months died of bronchopneumonia. However there were four other deaths in the placebo group in patients who were never treated with azathioprine. Three of these died of neoplasia, and it is interesting to speculate on the conclusions which might have been drawn had the deaths occurred in the azathioprine-treated group. All patients were examined for lymphadenopathy and hepatosplenomegaly but no unexplained abnormalities were detected. Liver function studies were normal in all patients taking azathioprine.

\section{Discussion}

The mode of action of azathioprine in rheumatoid arthritis is not known. Denman et al. (1970) were unable to show that it had immunosuppressive activity in patients with rheumatoid arthritis and Still's disease. Azathioprine has an anti-inflammatory action in some animals (Arinoviche and Loewi, 1970) and it has been suggested that it may have a similar effect in man (Philips et al., 1967).

Treatment with azathioprine is associated with an increased incidence of lymphoma in NZB mice (Casey, 1968). Penn and Starzl (1970) reviewed nine cases of malignant lymphoma in renal homograft recipients treated with azathioprine and steroids. In these cases the cause of the malignancy could be due either to immunosuppressive therapy or to the antigenicity of the homograft. Sjögren's syndrome predisposes to the development of tumours of the reticuloendothelial system (Talal et al., 1967) and it is possible that patients with rheumatoid arthritis and Sjögren's syndrome are doubly at risk when treated with azathioprine. This drug has also been shown to be teratogenic in some animals (Rosenkrantz et al., 1967). In view of these observations the use of immunosuppressive therapy in non-malignant disease should clearly be restricted to patients who meet strict criteria (Schwartz and Gowans, 1971). Nevertheless, azathioprine seemed to be relatively safe in this group of patients over a period of 30 months. Regular blood counts are, of course, mandatory (one patient, for example, developed neutropenia for the first time after 24 months' treatment). It is suggested that blood counts be performed weekly for the first 2 months and thereafter at monthly intervals.

It is disappointing that no further significant fall in steroid requirements could be detected after 12 months. However, only a small number of patients remained in the study after this time and there were considerable changes in the organization of the trial. On the other hand, the benefit observed may reflect the maximum therapeutic effect that can be obtained without unacceptable toxicity.

When azathioprine is being used in an attempt to reduce steroid dosage, it is suggested that a 12-month course of treatment should be attempted in the first instance. There is probably no point in treating patients for longer than this if they do not respond. If azathioprine is discontinued after 12 months, it is possible that those patients who respond can be maintained for some time on a dose of steroids significantly lower than their pretreatment level. Evidence for this, however, is based on small numbers of patients, and more work is needed on this aspect.

We should like to thank Dr. Michael Mason for his help in preparing this paper.

\section{References}

Arinoviche, R., and Loewi, G. (1970) Annals of the Rheumatic Diseases,

29, 32. Casey, T. (1968). Clinical and Experimental Immunology, 3, 305

Currey, H. L. F. (1971). In Modern Trends in Rheumatology-2, ed. Alan G. S. Hill, p. 174. London, Butterworths.

Denman, E. J., Denman, A. M., Greenwood, B. M., Gall, D., and Heath, R. B. (1970). Annals of the Rheumatic Diseases, 29, 220.

Mason, et al. (1969). British Medical fournal, 1, 420.

Penn, I., and Starzl, T. E. (1970). International fournal of Clinical Pharmacology, Therapy and Toxicology, 3, 49.

Philips, V. K., Bergen, W., and Rothermich, N. O. (1967). Arthritis and Rheumatism, 10, 305.

Rosenkrantz, J. G., Githens, J. H., Cox, Sheila, M., and Kellum, D. L. (1967). American fournal of Obstetrics and Gynecology, 97, 387 .

Schwartz, R. S., and Gowans, J. D. C. (1971). Arthritis and Rheumatism, 14,134 .

Talal, N., Sokoloff, L., and Barth, W. F. (1967). American Fournal of Medicine, 43, 50. 